\title{
HERNÁN RUIZ III Y LAS OBRAS DE LA IGLESIA PARROQUIAL DE LA ASUNCIÓN DE LUQUE (CÓRDOBA)
}

\author{
HERNÁN RUIZ III AND THE WORKS OF NTRA. SRA. DE \\ LA ASUNCIÓN'S CHURCH IN LUQUE (CORDOBA)
}

\author{
Juan LuQue CARrillo \\ juanluque317@gmail.com
}

\begin{abstract}
El presente trabajo reúne una serie de datos sobre el arquitecto cordobés Hernán Ruiz III y su intervención en la iglesia de Nuestra Señora de la Asunción de Luque. La documentación consultada en el archivo parroquial de la villa sitúa al maestro en los años finales del Quinientos al frente de la obra con el cargo de maestro mayor. El inicio, proceso y fin de la construcción se analizarán mediante la información de los registros de visitas pastorales y libros de cuentas de fábrica estudiados.

Palabras clave: Hernán Ruiz III, Luque, siglo XVI, parroquia de Nuestra Señora de la Asunción, cantería.
\end{abstract}

This work compiles a series of data on the Cordobés architect Hernán Ruiz III and his intervention in Ntra. Sra. De la Asunción's church in Luque. The documentation consulted in the parochial file of the town places the teacher in the late years of the $16^{\text {th }}$ century at the head of the work with the position of main teacher. The beginning, process and finish of the construction will be analyzed by using information from the records of pastoral visits and studied account books of factory.

Keywords: Hernán Ruiz III, Luque, 16th Century, Ntra. Sra. De la Asunción's church, stonework.

En 1993 Estrada Carrillo ofreció la revisión más completa y documentada sobre la parroquia de Nuestra Señora de la Asunción de Luque ${ }^{1}$. En su trabajo se ponía de manifiesto todo el proceso de construcción del cuerpo de la iglesia, capillas, torre, retablo mayor y los desaparecidos coro y púlpito que en su día formaron parte de los bienes muebles del templo y que hoy, como consecuencia de las

${ }^{1}$ ESTRADA CARRILLO, Vicente: La iglesia parroquial de Luque (1567-1992). Córdoba, 1993. 
obras de la década de 1960, aparecen despiezados y repartidos por distintas dependencias. El presente trabajo parte de dicho estudio y de la información inédita suministrada por documentos del archivo parroquial, permitiendo trazar una línea cronológica con las principales obras llevadas a cabo en la iglesia, desde las primeras intervenciones fechadas en 1569, hasta las restauraciones de los años 1987-1992.

La obra de la iglesia mayor de la Asunción puso el broche final al siglo XVI en Luque, y produjo en la villa una actividad constructiva hasta entonces desconocida, como prueban diversas fuentes documentales. En esta ocasión, se ha optado por el estudio de los libros de las visitas pastorales y de cuentas de fábrica custodiados en el archivo de la parroquia, secciones en su día consultadas por Estrada Carrillo, y que han sido revisadas con el fin de aclarar y documentar la intervención de Hernán Ruiz III en el conjunto de la obra.

Las primeras noticias sobre la misma datan de 1567. En septiembre de este año el obispo don Cristóbal de Rojas y Sandoval (1562-1571)2, tras haber visitado la villa, mandó redactar un decreto para dar comienzo a las obras de la parroquia. Para ello, el prelado propuso la demolición de las dos iglesias medievales de Santa María y Santa Cruz y en su lugar levantar un nuevo y majestuoso templo mayor, reflejo del poder de la diócesis y de los nuevos planteamientos artísticos que desde hacía décadas se venían desarrollando en Córdoba y su catedral. La decisión, ajustada a la realidad del momento en la villa, fue sin duda la más acertada. La parroquia de Santa Cruz, además de sus limitadas dimensiones, estaba en muy malas condiciones de conservación, del mismo modo que debía estar también la de Santa María, pues los testimonios recogidos en los libros de visitas pastorales hacen referencia continuamente a la pobreza de su fábrica y a la poca actividad litúrgica que ofrecía a la feligresía ${ }^{3}$.

Tras el decreto de construcción, el obispo encargó el trazado de la nueva iglesia al cantero Sebastián de Peñarredonda, el colaborador más directo de Hernán Ruiz “el Joven”, y al maestro de obras del obispado Bartolomé Ruiz. Así se expresa en el texto pastoral de la visita de 1567, donde se especifica la cantidad de 4.226 maravedíes destinada a ambos arquitectos por la traza y planta del templo ${ }^{4}$. El sitio elegido para la nueva iglesia fue el extremo noroeste de la antigua fortaleza medieval que existió en la villa desde la época de dominación islámica, y que hacía esquina con un torreón del lienzo de muralla.

${ }^{2}$ GÓMEZ BRAVO, Juan: Catálogo de los obispos de Córdoba y breve noticia histórica de su Iglesia Catedral y Obispado. Córdoba, 1778, t. II, p. 468.

${ }^{3}$ ARJONA CASTRO, Antonio y ESTRADA CARRILLO, Vicente: Historia de la villa de Luque. Córdoba, 1977, p. 314.

${ }^{4}$ A. P. L. (Archivo Parroquial de Luque. Sección Visitas Generales), Libro 2: 15581572, Visita de 1567 , s/f. 
La visita general del año 1569 deja de manifiesto una serie de hechos de cierta relevancia en el conjunto de las primeras obras del templo, entre las cuales está la extracción de la piedra de la llamada cantera local del Tajo. Aunque la acción del tiempo ha borrado mucho las huellas, son perceptibles aún hoy en día los cortes y hondonada que testimonian esa extracción. En esta misma visita también se da una relación con los gastos de primera hora y los motivos por los que el obispo decidió emprender la construcción del templo ${ }^{5}$. La cuenta que sigue comprende la adquisición de dos casas, la visita de los canteros Cristóbal de Guerra, Bartolomé Ruiz y Pedro Gómez, la compra de espuertas, sogas, arena, ladrillos, cal, agua y otros gastos de jornales, andamios, un carretón para subir la piedra y materiales de hierro. Esta visita de Cristóbal de Guerra, Bartolomé Ruiz y Pedro Gómez tuvo por objeto la inspección del lugar donde se construiría la iglesia ${ }^{6}$. Una visita más a Luque del arquitecto Bartolomé Ruiz se documenta en estos años, así como el pago de honorarios por importe de 188.734 maravedíes en concepto de la tasación de la obra realizada por los maestros ${ }^{7}$. La edificación del templo alcanzó pronto un buen ritmo, como lo justifica la relación de gastos efectuados, la mayor parte de ellos relacionados con el aprovisionamiento de piedra ${ }^{8}$. Así, las primeras obras cometidas se centraron en la limpieza y allanamiento del solar, para inmediatamente dar comienzo a las labores de cimentación.

No obstante, al poco tiempo de comenzarse las obras, el obispo comienza a desconfiar del trabajo de Bartolomé Ruiz. La visita de 1572 informa al respecto: "El senor uisitador mando al dicho obrero que no le de mas maravedis algunos asta tanto que de siguridad y fianças de los maravedis que tiene reciuidos y de los que mas se le dieren y que la obra que a echo y que haze sera buena y fixa a uista de ofiçiales peritos en el arte y que se obliguen que si la obra no fuere tal debolbera los maravedis que se le ouieren dado e pagaran las costas danos y menoscabos que a la esta yglesia se le an seguido y siguieren lo qual se lo notifico al este Diego della Quadra obrero e lo consintio e firmo de su nonbre presentes por testigos Juan Ualera uicario desta villa y Andres Clauijo estante en ella"9. Todo parece indicar que el problema entre el maestro y el obispo se debe al parón que sufrió la construcción desde el 14 de abril de 1572 hasta el 15 de marzo de 1576. El obispo no concibe esta inactividad y empieza a cuestionar la implicación del maestro en el proyecto. El desencuentro debió agudizarse pues, a partir del 27 de marzo de 1577, empieza a aparecer Hernán Ruiz III como nuevo maestro mayor de obras en las cuentas presentadas al obispado ${ }^{10}$.

\footnotetext{
${ }^{5}$ Ibídem.

${ }^{6}$ Ídem, Visita de 1569, s/f.

${ }^{7}$ Ibídem.

${ }^{8}$ Ídem, Visita de 1572, s/f.

${ }^{9}$ Ibídem.

${ }^{10}$ ESTRADA CARRILLO, Vicente: La iglesia parroquial..., op. cit., p. 17.
} 


\section{LA DÉCADA DE 1580: EVOLUCIÓN DEL TEMPLO}

En la visita de 1577 puede verse cómo el contrato con Bartolomé Ruiz entra en crisis, motivo por el cual se lleva a cabo la liquidación de su trabajo según la tasación hecha por Hernán Ruiz quien, a partir de ese momento, asumirá la dirección de la obra ${ }^{11}$. Será, pues, a partir de ese año cuando el arquitecto cordobés tome la dirección de la fábrica parroquial, encargándose más adelante de la traza de la torre ${ }^{12}$. Ésta, aunque proyectada en 1592 y terminada por Eufrasio López de Rojas a mediados de la centuria siguiente, se trata de un monumental campanario compuesto de tres cuerpos de idéntico grosor, aunque de diferentes alturas, y un cuarto tramo dedicado a cuerpo de campanas. Sobre la austera elegancia de los tres primeros módulos, se eleva el último, que rompe la sobriedad del estilo de Hernán Ruiz al incorporar un diseño, el que introduce el arquitecto jienense, más sofisticado, con dieciséis columnas de orden compuesto que muestran capiteles con volutas y frutas colgantes, sobre los cuales descansa una cornisa compuesta por cuatro pedestales en las esquinas, apareciendo en cada una de ellas sendas bolas flamígeras. Finalmente, una cúpula cónica rematada con una bola de piedra y una cruz de hierro labrada corona el conjunto.

Lejos de incorporar cambios y novedades a la fábrica parroquial, Hernán Ruiz III siguió trabajando sobre lo trazado por Sebastián de Peñarredonda, Cristóbal de Guerra y Bartolomé Ruiz. La obra recuperó su actividad pues en las partidas de gastos correspondientes a los siguientes años, se registran importantes inversiones en piedra, cal y arena.

El resultado es una monumental e interesante iglesia de tres naves. La central, además de mostrar mayores dimensiones respecto a las laterales, aparece cubierta con una techumbre de madera de mediados del siglo XVII, obra de los carpinteros cordobeses Pedro Palomino y Luis de Valverde ${ }^{13}$. Los formeros de medio punto apean sobre pilares que recuerdan por su composición algunos de los trazados por Hernán Ruiz "el Joven” y la cabecera aparece compartimentada en tres capillas con testero plano: la central desempeña la función de capilla mayor y su cubierta muestra una cúpula sobre pechinas decorada con motivos geométricos derivados de los empleados en la capilla del Espíritu Santo de la catedral

11 "Descargensele mas cinquenta e nueue mill e ciento cinquenta e ocho maravedis que ha pagado a Bartolome Ruiz maestro que fue de la obra nueua de la dicha yglesia para en quenta de la obra que se hizo en la dicha yglesia que le fue tasada por Hernan Ruiz maestro maior de las obras deste obispado en seiscientos e setenta e nueue mill e dozientos e ochenta e siete maravedis e para acaballe de pagar la dicha quantia se le quedan a deuer tres mill quinientos e conquenta e nueue maravedis mostro conocimiento". A. P. L. Sección Visitas Generales, Libro 3: 1577-1581, Visita de 1577, s/f.

${ }_{12}$ Ibídem

13 VILLAR MOVELLÁN, Alberto, DABRIO GONZÁLEZ, Ma Teresa y RAYA RAYA, Ma Ángeles: Guía artística de Córdoba y su provincia, Córdoba, 2006, p. 501. 
cordobesa $^{14}$. La de la izquierda es la capilla del Sagrario y está presidida por una majestuosa talla de la Inmaculada relacionada con el círculo granadino de Alonso de Mena ${ }^{15}$. Finalmente, la de la derecha es la primitiva capilla de la Cofradía de las Ánimas del Purgatorio, hoy del Sagrado Corazón, donde se venera dicha imagen en un sencillo retablo dorado del siglo XVIII de limitadas dimensiones ${ }^{16}$.

La obra avanza, como se puede deducir del testimonio de la visita de 1579, cuando se levantaban los muros y se trabajaba en la construcción de los arcos. Con motivo de la obra de la cubierta y la necesidad de madera para ello, en esta visita de 10 de abril de 1579 se recoge una partida de Hernán Ruiz por la visita realizada a la iglesia de Santa Cruz con el único fin de comprobar si era realmente necesario su derribo y aprovechar los materiales para la obra nueva ${ }^{17}$.

Las cuentas del periodo comprendido entre diciembre de 1579 y julio de 1580 van a presentar dos novedades de gran interés. Una, que por vez primera se tomará a Pedro Muñoz como obrero de la fábrica, cuando hasta el momento siempre había aparecido con el cargo Diego de la Cuadra, y la otra, la constatación del hermano de Hernán Ruiz III, Martín Ruiz Ordóñez, como maestro de la obra desde el 7 de septiembre de 1579 hasta el 2 de julio de $1580^{18}$. No obstante, Hernán Ruiz seguirá con la dirección como certifica una visita más que realiza en 1580 a la villa ${ }^{19}$. Mientras tanto, la labor de cantería continúa acaparando las partidas de gastos.

Entre junio de 1583 y enero de 1585 se aprecia un cambio en el desarrollo de la construcción. Las labores en piedra van a ir abriendo paso a la nueva fase de trabajo con la madera. Una vez que las arcadas y muros están ya levantados, albañiles y carpinteros conjuntan las tareas necesarias. Es el momento en que se incorporan los citados maestros Pedro Palomino y Luis de Valverde, carpinteros que llevarán en su totalidad el peso del enmaderamiento de las techumbres. Paralelamente a estas obras se llevará a cabo el desmantelamiento de la vieja iglesia de Santa Cruz, prácticamente en ruinas, respondiendo así a lo decretado años atrás por el obispo Rojas y Sandoval. Las maderas de sus tejados se reutilizarán y aprovecharán para la cubierta de la nave principal del nuevo templo. Poco después, en

${ }^{14}$ VILLAR MOVELLÁN, Alberto: "La arquitectura del Quinientos", en Córdoba y su Provincia, t. III. Sevilla, 1986, p. 226.

15 AA. VV.: Catálogo artístico y monumental de la provincia de Córdoba, Córdoba, 1993, t. VI, p. 37.

16 VILLAR MOVELLÁN, Alberto, DABRIO GONZÁLEZ, M ${ }^{\mathrm{a}}$ Teresa y RAYA RAYA, Ma Ángeles: Guía artística de Córdoba..., op. cit., p. 502.

${ }_{17}$ A. P. L. Sección Visitas Generales, Libro 3: 1577-1581. Visita de 1579, s/f.

${ }_{18}$ Ídem. Visita de 1580, s/f.

19 "Descargensele mas ocho ducados que pago a Hernan Ruiz maestro maior deste obispado por quatro dias que se ocupo en uenir a uer e dar traça en la dicha obra". Ibídem. 
la visita general de 1587, queda constancia de la demolición que se ha llevado a cabo en la iglesia de Santa $\mathrm{Cruz}^{20}$. Las cuentas de este periodo siguen exponiendo con suficiente claridad la intensa actividad de albañiles y carpinteros.

En la referida sección de visitas generales falta la realizada en el año 1590, y asimismo la correspondiente al 20 de marzo de 1591 tiene arrancados los veinte primeros folios, que posiblemente corrieran la misma suerte que el cuaderno de su antecesora. No obstante, en la obra Historia de la villa de Luque se transcribe un informe descriptivo del estado en que se hallaba el templo en el año 1590, y que por su interés se va a reproducir literalmente:

"Luego visito el cuerpo material de la dicha yglesia el cual no estaua acauado y su traza era de tres nabes con dos dansas de arcos de largo a largo de canteria blanca con molduras bien labrados y haria cada danza quatro arcos grandes y en el rremate de las dichas danzas de arcos dos arcos mas pequenos confinando con la capilla maior y otros dos enfrente de la capilla y el otro testero sobre el qual se ha de hazer el coro alto. Medio cuerpo de ella esta ataxado con una pared de tapieria y el otro medio cuerpo no esta acabado mas que los dos dichos arcos de canteria fixados con sus cimbras y como la mitad poco mas o menos de las paredes de la iglesya y el techo de la nave maior que estaba cubierto hera de madera de pino labrada de armadura y sobre la dicha capilla era de canteria el yieso de la boveda de media naranja pintado con una labor de yeseria a lo que parecia y el techo de las otras naves colaterales era de madera de pino labrada mas llano. En el altar maior no habia rretablo sino un tabernaculo de piedra de jaspe bien labrado y brunido con molduras y pyramides y parte embutido en el jaspe en piedra negra que hacia obra bien parecida con las puertas del sagrario de terciopelo carmesi con las guarniciones cerraduras llave y goznes dorados e quatro de los bordados de las dichas puertas de hilo de oro las cuales estaban forradas de rojo carmesí. El suelo de la yglesia no estaba solado. El organo en un tablado levadizo mientras no se acabe la yglesia. Tenia tres puertas triangulares la del mediodía salia a la plaza de la yglesia e otra era alta suntuosa y costosamente labrada. A los lados de la capilla maior habia dos capillas medianas los texos y se va hazer un canpanario sobre una torre de la muralla antigua alzandola algo para ahorrar el gasto dando licencia para ello" ${ }^{21}$. Queda así descrito con minuciosidad el estado en que se hallaba la fábrica parroquial en los momentos previos a su terminación definitiva.

${ }^{20}$ Ídem. Libro 4: 1583-1587, Visita de 1587, s/f.

${ }^{21}$ ARJONA CASTRO, Antonio y ESTRADA CARRILLO, Vicente: Historia de la villa de Luque. Córdoba, 1977, pp. 92-93. 


\section{LA CULMINACIÓN DEL PROYECTO}

Del mismo modo que en los primeros años de las obras se produjo un enfrentamiento entre el obispo Rojas y Sandoval y el arquitecto Bartolomé Ruiz, un nuevo desencuentro tuvo lugar a finales de la centuria esta vez entre don Antonio Mauricio de Pazos y Figueroa (1582-1586) ${ }^{22}$ y Hernán Ruiz III. Las relaciones entre el arquitecto y la autoridad diocesana parecen entrar en crisis como consecuencia de la mala conducta y personalidad atrevida y aventurera del maestro, lo que hará que durante algunos años permanezca alejado y al margen de las obras del cabildo. En las cuentas comprendidas entre el 23 de marzo de 1590 y el 20 de marzo de 1591 son mínimos los gastos de obras registrados, haciéndose referencia únicamente al enlosado en mármol de la capilla mayor. Como novedad, deja de aparecer Hernán Ruiz en esta partida de cuentas y aparece como nuevo maestro mayor Juan de $\mathrm{Ochoa}^{23}$, cuya intervención se redujo exclusivamente a señalar las plantas de las sepulturas de la nave central del templo. En la visita de 1590 el visitador del obispado ordena la continuación de la obra y la traza de la torre conforme al modelo presentado por Ochoa ${ }^{24}$. No obstante, en las cuentas de 1 de marzo de 1592 vuelve a aparecer Hernán Ruiz dirigiendo las obras de la parroquia con cargo de maestro mayor. Una partida de gastos de ese año no deja lugar a duda ${ }^{25}$. La intervención de Juan de Ochoa no tuvo, por tanto, mayor trascendencia en el conjunto de la obra.

Los pagos de los siguientes años atienden exclusivamente a la terminación tanto de las naves, en avanzado estado de construcción, como de sus cubiertas. Así se hace constar en la visita de 1592, donde se especifica el gasto en concepto de la extracción de la piedra, cal, arena, pinos y mano de obra ${ }^{26}$.

En esta visita de 1592 se aporta también un dato muy curioso que informa del estado y evolución de la obra. Siendo vicario de la parroquia Pedro Sánchez de la Nava, y rector Pedro Urbano, el canónigo don Diego López de Fromesta visita la iglesia y celebra por primera vez misa aún sin estar terminada del todo ${ }^{27}$. Aunque habilitada para el culto, todavía quedaban pendientes de hacer algunas tareas importantes para la terminación del cuerpo de la iglesia. Una cuenta de gastos correspondiente a 1594 relata con detalle cada una de las partidas que se

${ }^{22}$ GÓMEZ BRAVO, Juan: Catálogo de los obispos..., op. cit., p. 522.

${ }^{23}$ Sobre este tema véase: VALVERDE MADRID, Juan: "Juan de Ochoa, el arquitecto de la catedral cordobesa", Omeya, 14, 1970, s/p.

${ }^{24}$ A. P. L. Sección Visitas Generales, Libro 5: 1587-1599, Visita de 1590, s/f.

25 "Mas se le descarguen ocho ducados que pago a Hernan Ruiz maestro maior de las obras deste obispado de uenir de Cordoua a esta uilla a ber la yglesia y dar traça como se habia de hazer la torre con mandamiento del senor visitador que mostro carta de pago de quatro dias a dos ducados". Ibídem.

${ }^{26}$ Ídem. Visita de 1592, s/f.

${ }^{27}$ Ibídem 
van invirtiendo para acabarla. En ella se incluyen los jornales de canteros, albañiles y peones durante 63 semanas, la extracción de la piedra, su labranza, otros materiales como cal, yeso, agua, madera y tejas y los viajes de Benito Hernández, maestro carpintero cordobés, a la villa de Luque para sacar a subasta la obra de las techumbres. Todo ello supuso un coste de 555.268 maravedíes $^{28}$.

En la visita de 1595 se aclara la necesidad de abrir al culto la nueva parroquia cuando todavía no estaba terminada de edificar. La razón es que la antigua parroquia de Santa María había dejado de servir a la feligresía del pueblo al derrumbarse por completo. Arruinada y sin intención de edificarla para darle ni siquiera el rango de ermita, sus restos parecían correr la misma suerte que los de la desaparecida parroquia de Santa Cruz. De hecho sus materiales serían aprovechados para terminar las obras de la nueva fábrica parroquial ${ }^{29}$.

En este estado, las obras de terminación del templo mantienen su curso. Los tejados se están completando, la techumbre de la nave central acababa de pintarse y el contrato de carpintería vuelve a reunir a los maestros Luis Valverde y Pedro Palomino para finalizar las obras de las cubiertas. Las partidas de gastos todavía presentan importantes cantidades destinadas a la extracción de piedra, sin especificarse el destino concreto de la misma ${ }^{30}$. De este modo puede verse cómo el final de la centuria traerá consigo la terminación de las obras del templo. Se liquida la cuenta pendiente con los carpinteros, que dan por terminada su faena, y los albañiles rematan las últimas tareas. Para adecentar y proteger el interior del espacio, se colocaron unas majestuosas puertas de madera con clavos grandes de latón y mascarones que se realizaron en Córdoba, siguiendo el modelo de las realizadas años antes para la portada de Santa Catalina de la catedral cordobesa. Todo ello se relata en las cuentas correspondientes al año 1597, donde sigue apareciendo Hernán Ruiz como maestro mayor ${ }^{31}$.

Las cuentas de los años próximos ya no tendrán ninguna consignación de obra nueva, salvo los gastos en concepto de las obras de las capillas del muro occidental, que son tres: la del presbítero don Rodrigo Calvo de León ${ }^{32}$, hoy capilla de San José, la del gobernador de la villa, don Juan de Villegas y Ceballos, y la de Nuestra Señora del Carmen.

Concluye así el siglo y con él, la obra de la nueva iglesia parroquial, que se pondrá bajo la advocación de Nuestra Señora de la Asunción. Habían pasado 30

${ }^{28}$ A. P. L. Sección Visitas Generales, Libro 5: 1592-1599, Visita de 1594, s/f.

${ }^{29}$ Ídem. T. 3, Libro nuevo de memorias, fol. 176.

${ }^{30}$ Ídem. Visita de 1595, s/f.

${ }^{31}$ Ídem. Visita de 1597, s/f.

${ }^{32}$ Sobre este tema véase: LUQUE CARRILLO, Juan: "Estudio histórico-artístico de la Capilla de San José de la Parroquia de Nuestra Señora de la Asunción de Luque -Córdoba-, y su vinculación con la familia Calvo de León", Ámbitos. Revista de Estudios de Ciencias Sociales y Humanidades, 29, 2013, pp. 73-80. 
años desde la publicación del decreto de don Cristóbal de Rojas y Sandoval: la nueva iglesia de Luque era ya una realidad.

De esta manera la villa se preparaba para dar comienzo a la centuria del XVII, cuyo trascurso quedó marcado por la crisis de mediados de siglo. Aunque sus consecuencias fueron especialmente perceptibles en los terrenos demográfico y económico, el acondicionamiento del interior de la parroquia, sin embargo, se llevó a cabo satisfactoriamente durante todo el Seiscientos, extendiéndose parte de la decoración final y adquisición del mobiliario litúrgico a los primeros años del siglo XVIII.

Fecha de recepción: 15 de septiembre de 2014

Fecha de aceptación: 28 de noviembre de 2014

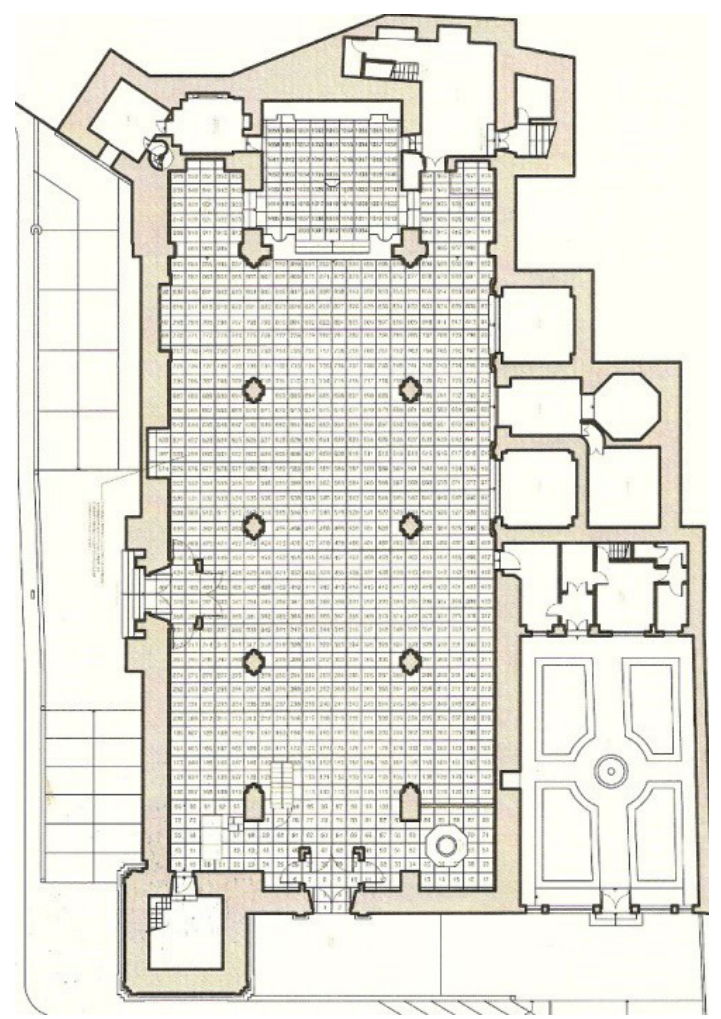

Figura 1. Planta de la iglesia. Sebastián de Peñarredonda y Bartolomé Ruiz. 1567. Fotografía del autor. 


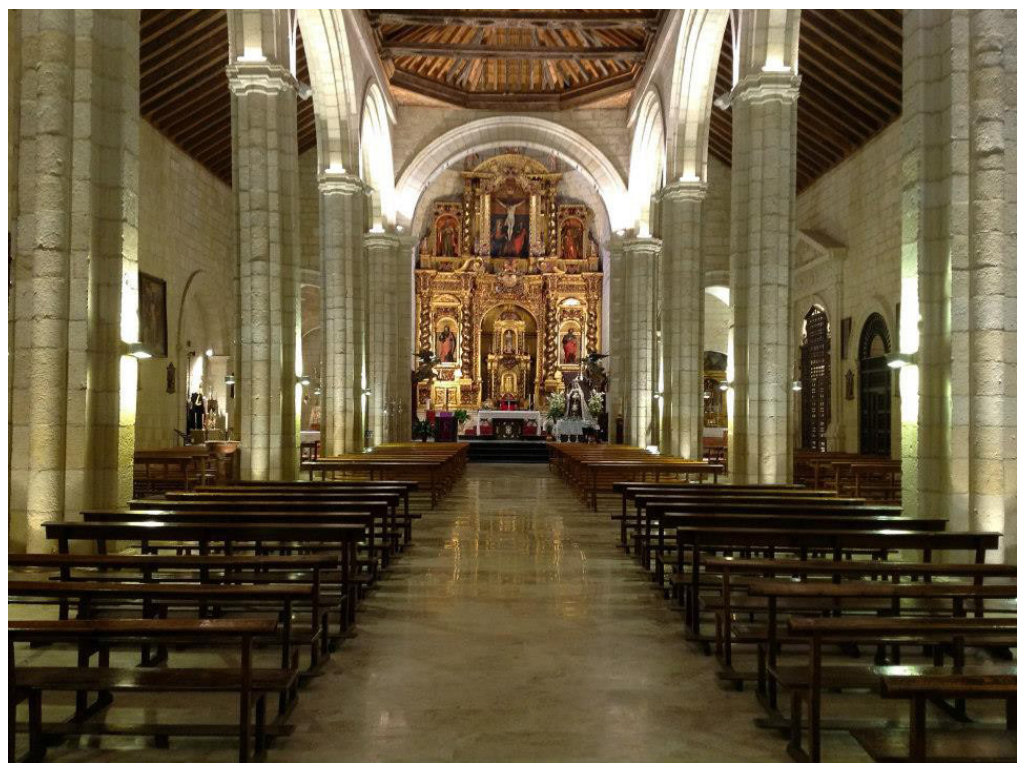

Figura 2. Interior. Nave central. Hernán Ruiz III. 1577-1591. Fotografía del autor.

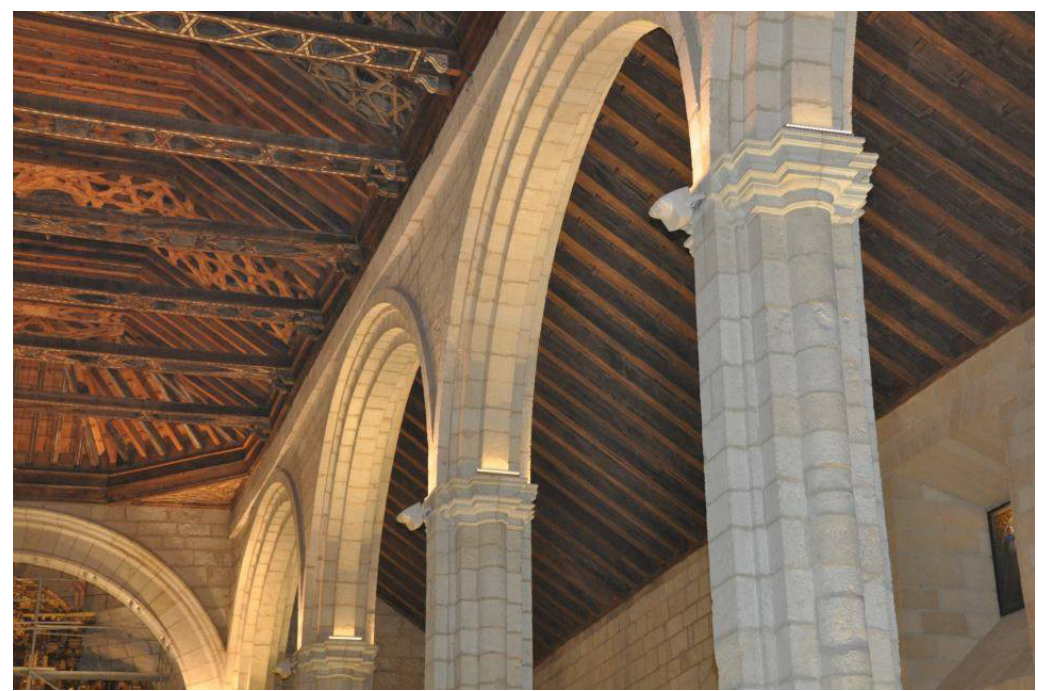

Figura 3. Detalle de las arcadas y techumbres. Fotografía del autor. 


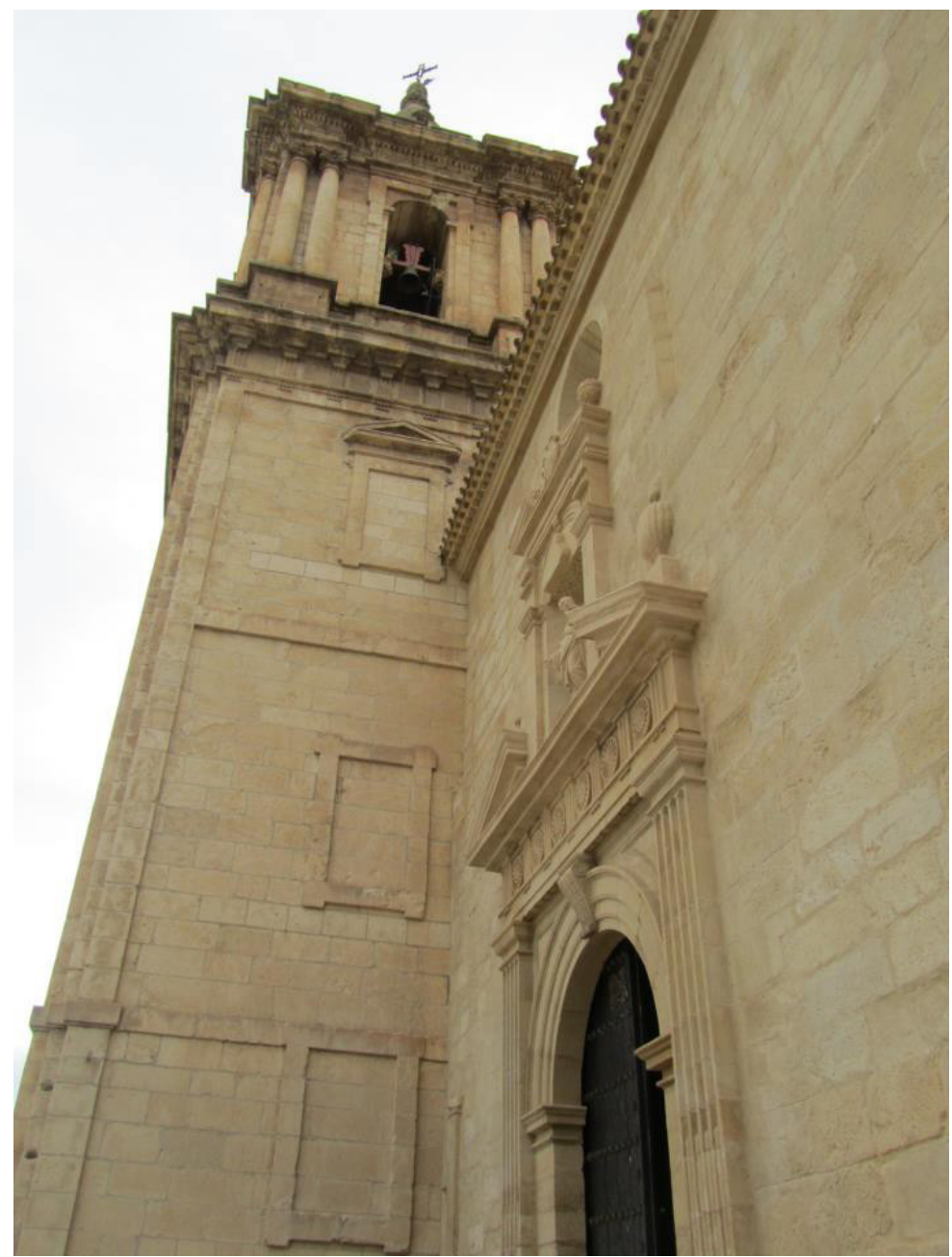

Figura 4. Vista de la torre desde la fachada occidental. Hernán Ruiz III y Eufrasio López de Rojas. 1592-1659. Fotografía del autor. 


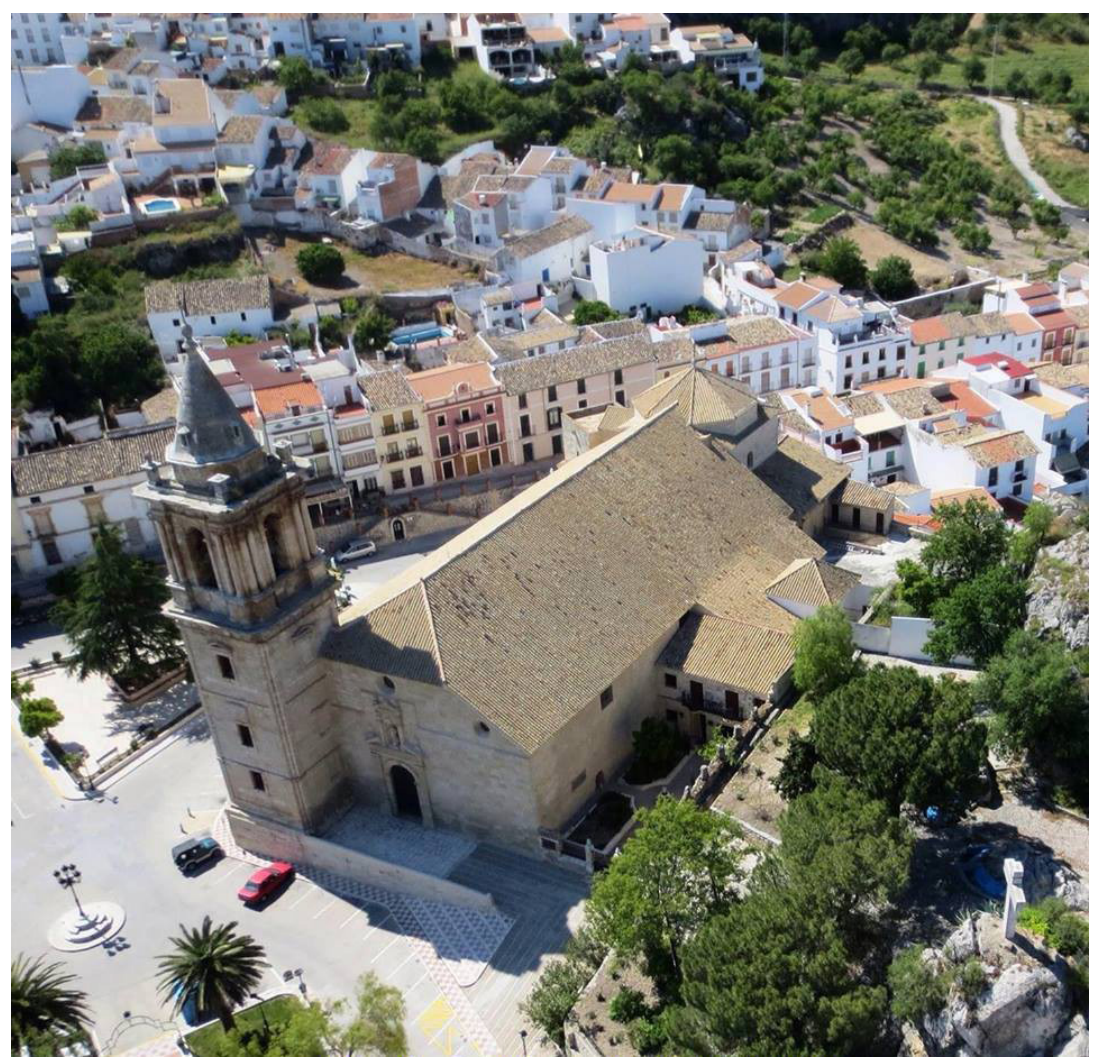

Figura 5. Vista aérea del templo. Fotografía del autor. 